\title{
INTERAÇÕES MORFO-BIO-CLIMÁTICA EM TRECHOS DO PARQUE NACIONAL DA SERRA DO CIPÓ: ASPECTOS PRELIMINARES
}

\author{
Antoniel Silva Fernandes ${ }^{(\mathrm{a})}$, Carolina Dias de Oliveira ${ }^{(\mathrm{b})}$, Wellington Lopes Assis ${ }^{(\mathrm{c})}$, Carlos \\ Henrique $\operatorname{Jardim}^{(\mathrm{d})}$
}

(a) Faculdade de Ciências Exatas e Tecnológias - FACET, Centro Universitário Newton Paiva, geoansf@yahoo.com.br

(b) Departamento de Geografia e História (DGH), CEFET-MG, geocarolina@ hotmail.com

(c) Departamento de Geografia (IGC) / Instituto de Geociências (IGC), UFMG, assisw@ gmail.com

(d) Departamento de Geografia / Instituto de Geociências (IGC), UFMG, cjardim@yahoo.com

\section{Eixo: CLIMATOLOGIA EM DIFERENTES NÍVEIS ESCALARES: MUDANÇAS E VARIABILIDADES}

\begin{abstract}
Resumo
Este trabalho pesquisou o comportamento das variáveis climatológicas de trechos do Parque Nacional da Serra do Cipó, em específico na confluência das sub-bacias dos Rios Bocaina e Mascates que originam o Rio Cipó, no município de Santana do Riacho/MG. A análise apoiou-se no enfoque da Climatologia Geográfica, associado à análise sistêmica e ritmo climático (MONTEIRO, 1971). Constatou-se a importância e a atuação de alguns elementos e fatores reguladores e controladores das condições climáticas que afetam o clima em microescala que, todavia, sofrem influência do clima regional, mostrando a integração entre o sistema superfície-atmosfera, dentro da qual se configura a ação humana capaz introduzir modificações na paisagem e comprometer a biota local.
\end{abstract}

Palavras chave:Climatologia Geográfica, Serra do Cipó, Análise Geossistêmica

\section{Introdução}

A interação entre os fatores e elementos climáticos e geográficos durante o processo de elaboração da paisagem compõe o sistema climático configurado por elementos dinâmicos e que reflete a troca permanente de energia e interdependência típico do Sistema Superfície-Atmosfera (SSA). E a Geografia por sua origem, a partir de uma visão geossistêmica sobre o meio, busca integrar as diferentes esferas terrestres para compreender os processos de produção e organização do espaço, e por isso, confere ao estudo do clima a singularidade de enviesá-lo através de uma conotação preferencialmente antropocêntrica a partir da relação sociedade-natureza (JESUS, 2008).

Conforme a definição de clima defendida por Sorre (2006), "o clima representa o ambiente atmosférico constituído pela série de estados atmosféricos sobre um lugar, em sua sucessão habitual”. E, partindo desta concepção, e de seu caráter de conjunto, síntese e dinamismo (variabilidade e ritmo) passam a nortear os 
estudos da Climatologia Geográfica a partir de meados do século XX. Por este motivo, a categorização das análises climatológicas em uma ordem de grandeza escalar se torna fundamental para as pesquisas com esta abordagem, e que, ao mesmo tempo denota uma conotação geográfica sobre a espacialização dos elementos e fenômenos atmosféricos, tentando explicar a dinâmica processual dos estudos do clima. Cabe destacar que tais grandezas escalares atribuídas ao estudo do clima apresentam uma abordagem diferenciada entre geógrafos climatólogos e meteorologistas, em que os primeiros priorizam a questão espacial e os segundos embasam a análise sob um viés temporal.

Jesus (2008) aponta que a organização das escalas espaciais e temporais do clima foram apresentadas, pioneiramente pelos franceses, em especial no trabalho de Scaetta (1935, citado por SORRE, 2006), mas confere à Monteiro (1971) a proposta de uma organização taxonômica para os espaços zonais, regionais e locais, topoclima, mesoclima, microclima, entre outras. Dentre as diversas formas de hierarquização, a mais aceita pelos climatólogos e meteorologistas subdivide as ordens de grandeza em: macroclima, mesoclima e microclima. Esta ocorre em função da diferenciação do ambiente atmosférico, regido por um conjunto integrado de fenômenos que se encadeiam e se superpõem no tempo e no espaço, sob as mais diversas ordens de grandeza e que convivem de modo concomitante, em regimes de trocas de energia recíprocas e interdependentes, segundo níveis de escala hierarquizados, tais como: dimensão, duração, frequência e intensidade em relação aos fenômenos atmosféricos. Tendo como premissa esta categorização, entende-se que o presente estudo se configure como uma análise climática de mesoescala, associado ao clima regional, definido a partir das influências produzidas pelos fatores geográficos controladores do clima, dentre os quais se exemplifica a orientação e a disposição dos grandes conjuntos orográficos; as condições topográficas predominantes; a posição latitudinal e a exposição da região e a participação dos sistemas atmosféricos responsáveis pelas mudanças diárias e semanais do tempo meteorológico, dentre os quais destacam-se: massas de ar, sistemas frontais e linhas de instabilidade.

Os climas regionais se caracterizam por uma ordem temporal de duração de várias horas a alguns dias e apresentam extensão horizontal aproximada entre 150 a 2 mil quilômetros e verticalmente são limitados por fenômenos que ocorrem na baixa troposfera. Tal proposição se alinha com a noção de climas regionais apresentada por Sorre (2006), ao afirmar que

não há talvez, no globo, dois locais cujos climas sejam idênticos. Porém, a ação dos fatores do clima produz uma generalidade suficiente para que tenhamos praticamente o direito de considerar, acima dos climas locais, os climas regionais. A noção de clima regional é uma etapa do caminho da abstração. Ela se aproxima o mais possível da realidade concreta na região onde o jogo do dinamismo atmosférico é o mais simples e onde a topografia é a mais uniforme. (...) Por outro lado, quando a topografia revela uma 
grande variedade como nas regiões de montanha, o clima regional é simplesmente uma associação de climas locais, estacionais (...) (SORRE, 2006, p.91, grifo nosso).

Tais características se aplicam à área de análise deste estudo, e estão inseridas em trechos do Parque Nacional da Serra do Cipó (PNSC) em Minas Gerais. E o objetivo deste estudo consiste em analisar as variáveis morfo-bio-climáticas destas áreas, próximas à confluência das sub-bacias hidrográficas dos Rios da Bocaina, Mascates e Cipó. Para a análise dos climas regionais entende-se que são necessários a identificação do ritmo anual, sazonal e mensal dos elementos do clima que representem os mecanismos da atuação dos sistemas de circulação atmosférica secundária. Esta deve ser complementada com a interferência de fatores geográficos regionais que definem cada domínio climático, bem como pela análise de cartas sinóticas e imagens de satélite meteorológicos, apoiadas ainda por informações e dados de estações meteorológicas de superfície (JESUS, 2008).

\section{Materiais e Métodos}

Os procedimentos metodológicos consistiram, inicialmente, na realização de pesquisas bibliográficas e busca de dados climáticos através da consulta as Normais Climatológicas do período 1961-1990 divulgados pelo Instituto Nacional de Meteorologia (INMET, 2009), as cartas sinóticas divulgadas pelo Centro de Previsão do Tempo e Estudos Climáticos - CPTEC e pela Marinha do Brasil, e as Imagens de Satélite disponibilizadas pelo CPTEC. Tanto as cartas sinóticas quanto as imagens de satélites se referem às datadas do período da ida a campo. Na sequência, foi realizado um levantamento espacial da área objeto de estudo por meio da análise de cartas topográfica e geológica e pela construção de um banco de dados geográfico, que consistem em agrupar os dados cartográficos pertencentes à área de estudo, utilizados na elaboração dos mapas temáticos. Também foram empregadas técnicas de geoprocessamento, com auxílio do software ArcGis (versão 10.1). As bases de dados geográficas foram fornecidas, principalmente, pelo Instituto Estadual de Florestas - IEF. As cartas topográfica e geológica utilizadas foram as folhas Baldim (IBGE, 1975 e CODEMIG, 2012, respectivamente) ambas na escala de 1:100.000. O trabalho de campo foi realizado nos dias 6, 7 e 8 de maio de 2016 no Parque Nacional da Serra do Cipó localizado na porção pertencente ao município de Santana do Riacho/ MG, nas proximidades da rodovia MG-010 (FIG.1). Na atividade de campo foram realizados os seguintes procedimentos: percurso sobre os diferentes ambientes do Parque buscando identificar as diferenças climáticas do local através da leitura de dados como temperatura e umidade relativa do ar, prioritariamente. As áreas de interesse foram fotografadas e parte deste acervo compõe este artigo. Durante os trabalhos de campo realizou-se a captura de trilhas e pontos com o uso de receptores GPS - Sistema de Posicionamento Global de navegação das 


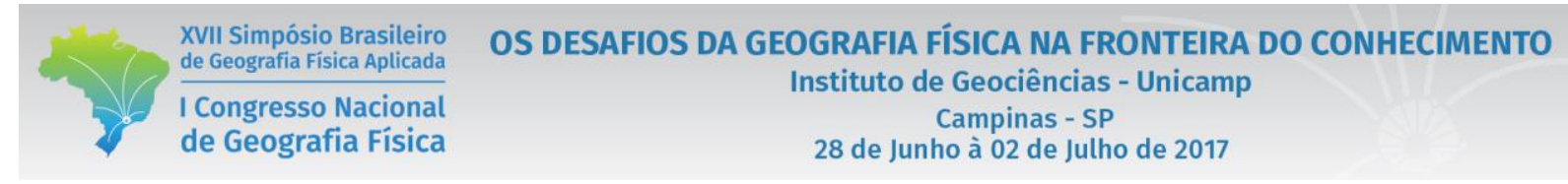

marcas e modelos Garmim 60 CSX e Magellan série eXplorist (versão 310). Também foram utilizados termômetros para leitura de temperatura na altura do solo em diferentes ambientes (solo exposto, relva, água, afloramento rochoso, dentre outros) e termohigrômetro para leitura de umidade relativa do ar, sendo que estes últimos foram obtidos nos pontos de interesse e, se constituíram em leituras móveis pontuais durante os dias de campo. Dados de temperatura, umidade relativa do ar e ponto de orvalho também foram coletados a cada hora, em quatro abrigos meteorológicos fixos durante o intervalo de 29 de abril ao dia 08 de maio de 2016 através de termo-higrômetro com data logger modelo modelo HT 4000, além da utilização de bússolas e material cartográfico de referência.

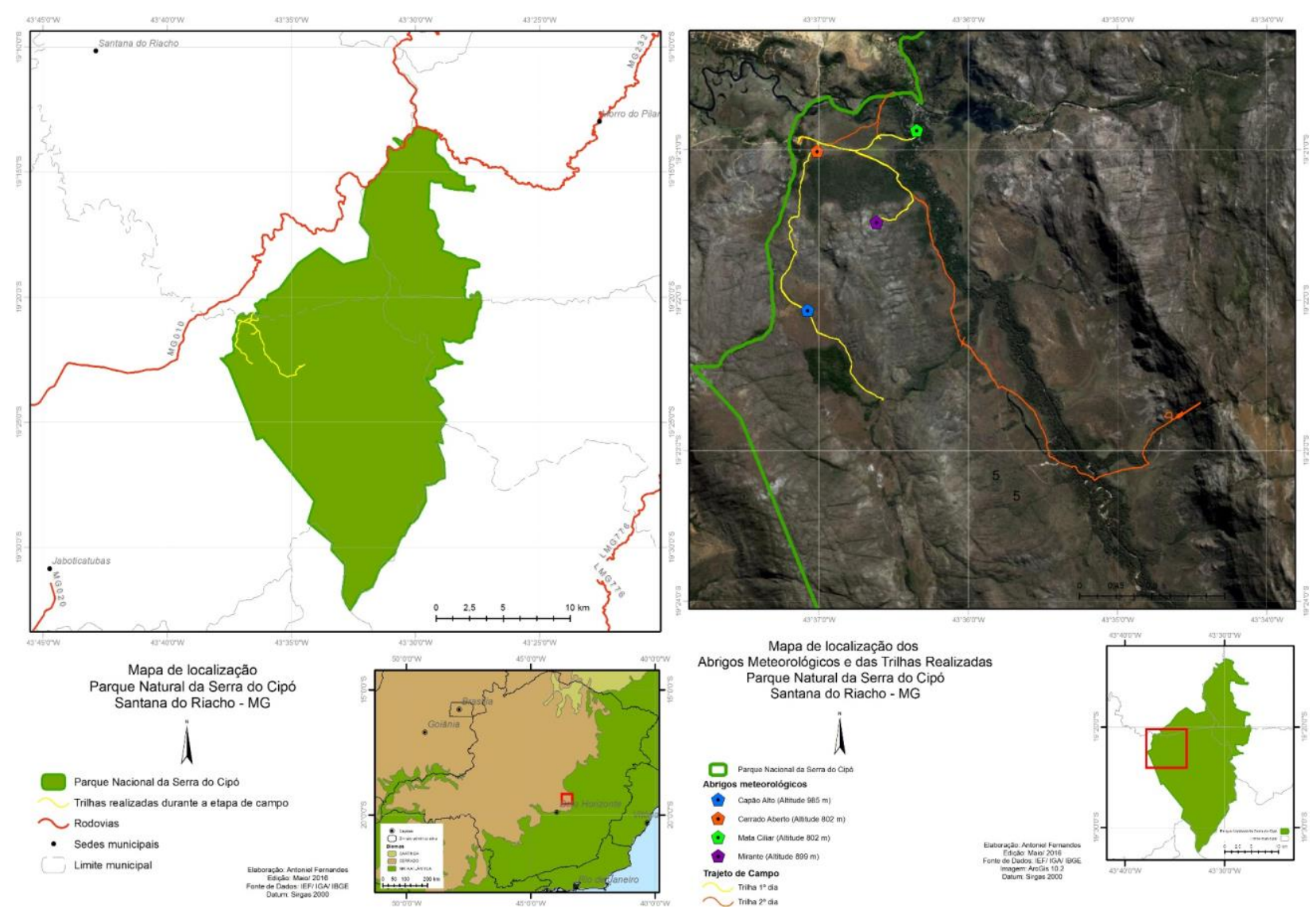

Figura 1 - Mapa de localização do PNSC e de localização dos Abrigos Meteorológicos e das Trilhas realizadas.

O clima predominante na região da Serra do Espinhaço é subtropical quente, composto por microclimas diversos associados a fatores da topografia. A média de temperatura anual varia entre $18^{\circ} \mathrm{C} \mathrm{e} 19^{\circ} \mathrm{C}$ com pluviosidade anual entre 850 a $1.400 \mathrm{~mm}$.

Os dados obtidos pelas coletas nos abrigos meteorológicos foram capturados em quatro pontos fixos instalados em locais com cobertura vegetal e altimetria distintas: um abrigo próximo à margem esquerda 
do Rio Cipó, a alguns metros a jusante da confluência entre os Rios Bocaina e Mascates, em vegetação de Mata Ciliar (Lat.19²0'50's e Long.43³6'19,6"WGr); outro ponto em área de Cerrado Aberto (Lat.19²0'58,8'’S e Long.43³6'59,6”WGr) em área de regeneração, ambos em mesma faixa altimétrica (802m); um terceiro ponto instalado em topo de morro da Serra da Lagoa Dourada, denominado Alto Capão (Lat.19²2'03'’S e Long.43³7’03,6”WGr) devido à cobertura vegetal ali presente, com altitude de $985 \mathrm{~m}$ e, por fim, um quarto ponto instalado em um Mirante (Lat.19²1'26,5'’S e Long.4336'35,5”WGr) com altitude de $899 \mathrm{~m}$ em área com vegetação típica de Campo Rupestre. Cabe ressaltar que os três primeiros pontos foram instalados no dia 29/04/2016, e o do Mirante foi instalado somente no dia 06/05/2016, o que exige uma análise relativizada deste em função da limitação de dados em comparação ás demais. Todos os abrigos registraram pontos a cada hora, durante 24 horas, e ficaram instalados até o dia 08/05/2016, sendo o último registro realizado às 6 horas da manhã.

A partir dos dados coletados nos abrigos realizou-se a tabulação e correção dos dados, sendo os aparelhos utilizados nos abrigos aferidos anteriormente com a Estação Meteorológica fabricada pela empresa Vaisala, modelo MAWS301, localizada na Estação Ecológica da Universidade Federal de Minas Gerais. A partir disso, foram produzidos gráficos para melhor ilustrar os resultados obtidos.

\section{Categorização da área em estudo}

O PNSC foi criado pelo Decreto Federal n 90.223, de 25 de setembro de 1984, possui área aproximada de 31.632 ha e é gerido pelo Instituto Chico Mendes de Conservação da Biodiversidade - ICMBio. Situa-se na porção meridional da Serra do Espinhaço, em parte dos municípios de Santana do Riacho, Jaboticatubas, Morro do Pilar e Itambé do Mato Dentro. A figura 1 localiza-se a área em estudo.

A etapa de campo concentrou-se na porção sudoeste da Serra das Bandeirinhas e na porção nordeste da Serra da Lagoa Dourada, conforme denominações regionais (figura 1). Entre elas, áreas mais aplainadas recortadas pelos cursos d'água do Rio Mascates e Rio da Bocaina, que ao se confluírem formam o Rio Cipó, que deságua no Rio Paraúna, afluente da margem direita do Rio das Velhas, e configura parte da bacia do Rio São Francisco.

As características pedológicas são decorrentes das características geológicas regionais, implicando em limitações ecológicas impostas por solos areno-quartzosos dos topos de serra, associadas à Formação do Supergrupo Espinhaço, além de solos eutrofizados presentes nas áreas limítrofes do orógeno. Todavia, tal limitação edáfica não impossibilita a riqueza florística dos Campos Rupestres da Serra do Cipó, registrando, conforme Menezes \& Giulietti (2000), citado por GONTIJO (2008), a presença de 1.590 espécies, dentre um total de 149 famílias, em uma área de aproximadamente $200 \mathrm{~km}^{2}$, destacando o 
elevado índice de endemismo da flora local, constatado em estudos anteriores. Tais espécies possuem diversos usos e aplicações para a sociedade e moradores locais, a exemplo da coleta de caules das canelasde-ema para utilização como combustível; a retirada de cactos, bromélias e orquídeas por colecionadores de plantas ou por extratores atraídos pelo elevado valor de mercado que estas possuem; além da extração das sempre-vivas para confecção de artigos artesanais, feitas de modo sistemático e generalizado ao longo do Espinhaço Meridional, e que impactam negativamente no desenvolvimento das espécies no Cerrado, podendo leva-las à extinção (GONTIJO, 2008). Ainda segundo este autor, o orógeno do Espinhaço se configura como um "mosaico de biomas", em função de sua diversidade florística e fitofisionômica, abrangendo o chamado quarto bioma, formado pelos Campos Rupestres de Altitude - que não se restringem à Serra do Espinhaço - mas aparecem como faixas de transição ou refúgios isolados em meio aos demais domínios vegetacionais predominantes, como a Mata Atlântica, o Cerrado e a Caatinga.

De modo específico, o PNSC localiza-se no bioma de Cerrado, conforme mapa de localização da figura 1, com fitofisionomia, nas partes que foram percorridas em campo, de Mata Riparia, Campos Rupestres e de Altitude, Capões, muitas vezes, fundindo-se com as florestas presentes nas áreas mais íngremes das vertentes dos anfiteatros e fundos de vale, bem como a vegetação característica de Cerrado em regeneração e vegetação antropizada por pastagem. O elevado grau de endemismo e a vegetação peculiar que protegem importantes áreas de nascentes e mananciais de água da região se tornam relevantes em termos de proteção e conservação de áreas verdes do estado mineiro. A existência de diversas cachoeiras e cursos d'água configuram como atrativos para as atividades de lazer e turismo da região, mas que devem se ater aos preceitos da sustentabilidade e aos princípios da preservação na medida em que passou a ser concebida como "Reserva da Biosfera da Serra do Espinhaço (RBSE) em 2006, após receber o reconhecimento pela UNESCO em 2005. A figura 2 ilustra parte da área em estudo. 


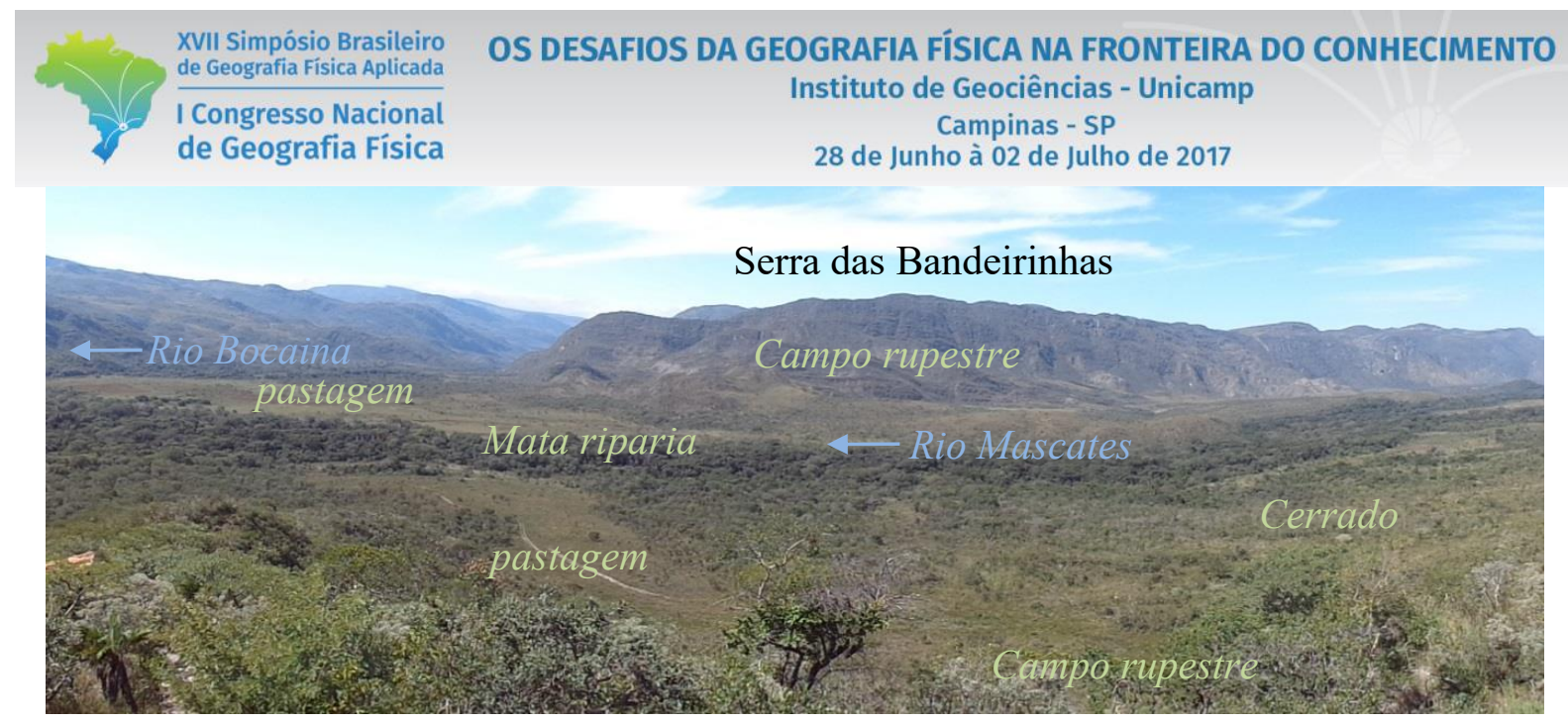

Figura 2. Vista geral da área em estudo no Parque Nacional da Serra do Cipó - Santana do Riacho/ MG.

Segundo Gontijo (2008), a deficiência hídrica marcada no período do solstício de inverno, propicia um elevado número de queimadas na região, e que se reflete em uma serie de adaptações morfológicas nas plantas para a sua sobrevivência. A área também sofre pressão antrópica pelo uso agrícola e pela ocupação desordenada da Cadeia do Espinhaço, arraigando conflitos entre jogos de interesse contraditórios dos profissionais que atuam na região. Tal cenário de impactos sistematizados que afetam a integridade ambiental do Orógeno do Espinhaço poderia, segundo Gontijo (2008), desencadear um grande "terremoto ambiental”, em analogia à própria orogênese da Cadeia do Espinhaço.

\section{Resultados e discussão}

A partir dos dados das Normais Climatológicas do período de 1961-1990 (INMET, 2009) para as estações localizadas nos municípios mais próximos a área investigada (Belo Horizonte, Conceição do Mato Dentro e Itabira), fez-se uma triangulação com a área em estudo localizada próximo ao centro, permitindo observar temperaturas médias anuais próximas a esses valores (TAB.1).

Tabela I. Médias de Temperaturas $\left({ }^{\circ} \mathrm{C}\right)$

\begin{tabular}{|c|c|c|c|c|c|c|c|c|c|c|c|c|c|}
\hline \multirow{2}{*}{ Município } & \multicolumn{13}{|c|}{ Mês } \\
\hline & Jan & Fev & Mar & Abr & Mai & Jun & Jul & Ago & Set & Out & Nov & Dez & Ano \\
\hline Belo Horizonte & 22,8 & 23 & 22,9 & 21,7 & 19,6 & 18,5 & 18 & 19,7 & 21,1 & 21,7 & 22,2 & 22,2 & 21,1 \\
\hline Conceição do Mato Dentro & 23 & 23,2 & 22,8 & 21 & 18,6 & 17,1 & 16,6 & 18,2 & 20 & 21,6 & 22,4 & 22,6 & 20,6 \\
\hline Itabirá & 22,2 & 22,3 & 21,6 & 20 & 18 & 16,4 & 15,7 & 17 & 18,7 & 20,3 & 21,1 & 21,2 & 19,5 \\
\hline
\end{tabular}

Fonte: InMet: Normais Climatológicas Itabirá (1931 a 1960) Belo Horizonte e Conceição do Mato Dentro (1961 a 1990)

Pela tabela II, nota-se que os valores de Umidade Relativa do Ar sobre a região em estudo permanecem elevadas praticamente o ano todo, segundo dados das Normais Climatológicas, com valores superiores a $70 \%$ para os três municípios em análise, e a precipitação anual superior a $1.400 \mathrm{~mm}$ (ver tabela III). Já a 
taxa de evaporação total no ano oscila de norte da área em estudo (836,1 mm - Conceição do Mato Dentro) para sudoeste $(1.206 \mathrm{~mm}$ - Belo Horizonte) e sudeste $(1.315 \mathrm{~mm}$ - Itabira) conforme ilustra a tabela IV.

Tabela II. Médias Mensais de Umidade Relativa do Ar (\%)

\begin{tabular}{|c|c|c|c|c|c|c|c|c|c|c|c|c|c|}
\hline \multirow{2}{*}{ Município } & \multicolumn{13}{|c|}{ Mês } \\
\hline & Jan & Fev & Mar & Abr & Mai & Jun & Jul & Ago & Set & Out & Nov & Dez & Ano \\
\hline Belo Horizonte & 79 & 75,1 & 74,7 & 73,9 & 72,5 & 71,4 & 68,7 & 64,5 & 65,1 & 69,8 & 74,1 & 78 & 72,2 \\
\hline Conceição do Mato Dentro & 75,7 & 75 & 77,9 & 79,4 & 80,3 & 79,2 & 74,8 & 70,7 & 68,5 & 72,9 & 76,2 & 78,2 & 75,7 \\
\hline Itabirá & 84,5 & 82,4 & 84,2 & 86,4 & 85,2 & 83,4 & 81,7 & 79,4 & 79,8 & 81,8 & 85,3 & 83,8 & 83,2 \\
\hline
\end{tabular}

Fonte: InMet: Normais Climatológicas 1961 a 1990.

Tabela III. Médias Mensais de Precipitação

\begin{tabular}{|c|c|c|c|c|c|c|c|c|c|c|c|c|c|}
\hline \multirow{2}{*}{ Município } & \multicolumn{13}{|c|}{ Mês } \\
\hline & Jan & Fev & Mar & Abr & Mai & Jun & Jul & Ago & Set & Out & Nov & Dez & Ano \\
\hline Belo Horizonte & 274,1 & 206,3 & 142,7 & 55,8 & 28,8 & 11,5 & 15,3 & 14,8 & 39,2 & 141,7 & 241,6 & 292 & 1463,7 \\
\hline Conceição do Mato Dentro & 279,9 & 168,5 & 131,9 & 72,1 & 22,5 & 15,7 & 18 & 10,4 & 43,8 & 163,8 & 265 & 267,1 & 1458,7 \\
\hline Itabirá & 160,8 & 130,3 & 121,2 & 82,4 & 35,8 & 20,8 & 23,9 & 19,4 & 66,7 & 137,2 & 243,5 & 273,9 & 1315,9 \\
\hline
\end{tabular}

Tabela IV. Médias Mensais de Evaporação Total (mm)

\begin{tabular}{|c|c|c|c|c|c|c|c|c|c|c|c|c|c|}
\hline \multirow{2}{*}{ Município } & \multicolumn{13}{|c|}{ Mês } \\
\hline & Jan & Fev & Mar & Abr & Mai & Jun & Jul & Ago & Set & Out & Nov & Dez & Ano \\
\hline Belo Horizonte & 88,1 & 81,2 & 93,5 & 92,3 & 90,8 & 89,5 & 103,3 & 132,9 & 143,6 & 117,6 & 90,8 & 82,4 & 1206 \\
\hline Conceição do Mato Dentro & 66,7 & 61,7 & 69,5 & 57 & 59,3 & 57,7 & 66,3 & 89,8 & 89,2 & 81 & 71,1 & 66,8 & 836,1 \\
\hline Itabirá & 160,8 & 130,3 & 121,2 & 82,4 & 35,8 & 20,8 & 23,9 & 19,4 & 66,7 & 137,2 & 243,5 & 273,9 & 1315,9 \\
\hline
\end{tabular}

Fonte: InMet: Normais Climatológicas 1961 a 1990.

Segundo análise sinótica divulgada nos sites do CPTEC e da Marinha do Brasil, para o período de coleta dos dados no PNSC (29 de abril a 08 de maio de 2016) e trabalhadas pelo meteorologista Heriberto Amaro $^{1}$, o sistema que predominou sobre a região sudeste foi a Anticiclone Subtropical do Atlântico Sul (ASAS) associada aos sistemas de alta pressão de origem oceânica. Na ocasião, houve a participação de uma frente fria $(\mathrm{FF})$ que atuou em todo o estado de Minas Gerais e provocou mudança no tempo na região de interesse, especialmente no início do período. Entretanto, no dia 05/05/2016, a frente fria se afastou do continente e avançou pelo oceano, e, em seguida, um novo sistema de alta pressão, Anticiclone Polar Migratório (APM), começou a ganhar força sobre o território argentino e avançou para o Brasil, porém com maior intensidade, cujo núcleo era de $1028 \mathrm{hPa}$. Essa onda de frio persistiu influenciando as condições atmosféricas sobre boa parte da Região Sudeste do Brasil, além de provocar acentuado declínio nas temperaturas. Finalmente, entre os dias 06 e 07/05/2016, um novo Anticiclone Polar Migratório realimentou a onda de frio e manteve o tempo estável em Minas Gerais, que apresentou temperaturas mais baixas até o dia 08/05/2016. A queda de temperatura e a predominância de um sistema de alta pressão foram confirmadas a partir dos dados obtidos pelos termohigrômetros, conforme será abordado adiante. Além do enquadramento sinótico, as imagens de satélites também ilustram a atuação desta frente fria

1 Meteorologista da PUC-Minas Contagem, responsável pelo Centro de Climatologia - PUC Minas Tempo Clima, na referida instituição, e aluno da disciplina que originou a coleta dos dados para a elaboração deste artigo. 


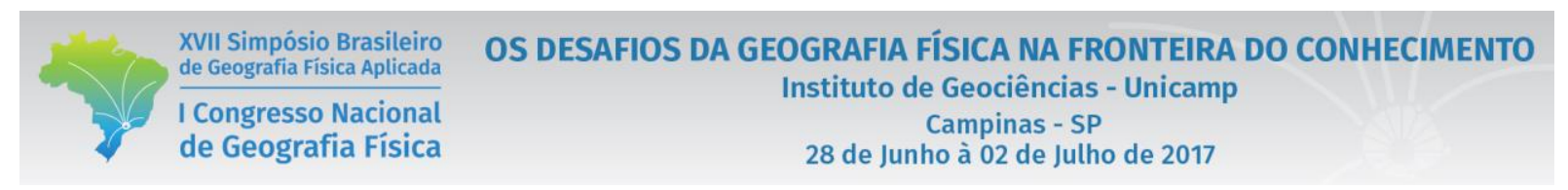

sobre a região sudeste do país e que favoreceu a formação de fenômenos de condensação sobre a área pesquisada, a exemplo do orvalho.

A partir desta configuração em escala sinótica do clima, é possível partir para a análise dos fatores locais, de modo a corroborar a metodologia de análise e ritmo climático definida por Monteiro (1971), associadas à análise morfo-bio-climática de Gontijo (2008) e da abordagem geossistêmica inerente à Climatologia Geográfica.

A figura 3 mostra o comportamento das médias diárias de temperatura, conforme dados extraídos em campo. Pela análise, nota-se diferença de $5^{\circ} \mathrm{C}$ acima para o abrigo do Mirante sobre os demais abrigos instalados. Isso pode ser explicado pelo fato de em seu entorno haver vegetação típica de Campo Rupestre e altitude de 899 metros, além de ter sido instalado em local de meia vertente e vale aberto em U, o que possibilita a formação de ventos anabáticos e movimentos de advecção ascendente de ar no vale.

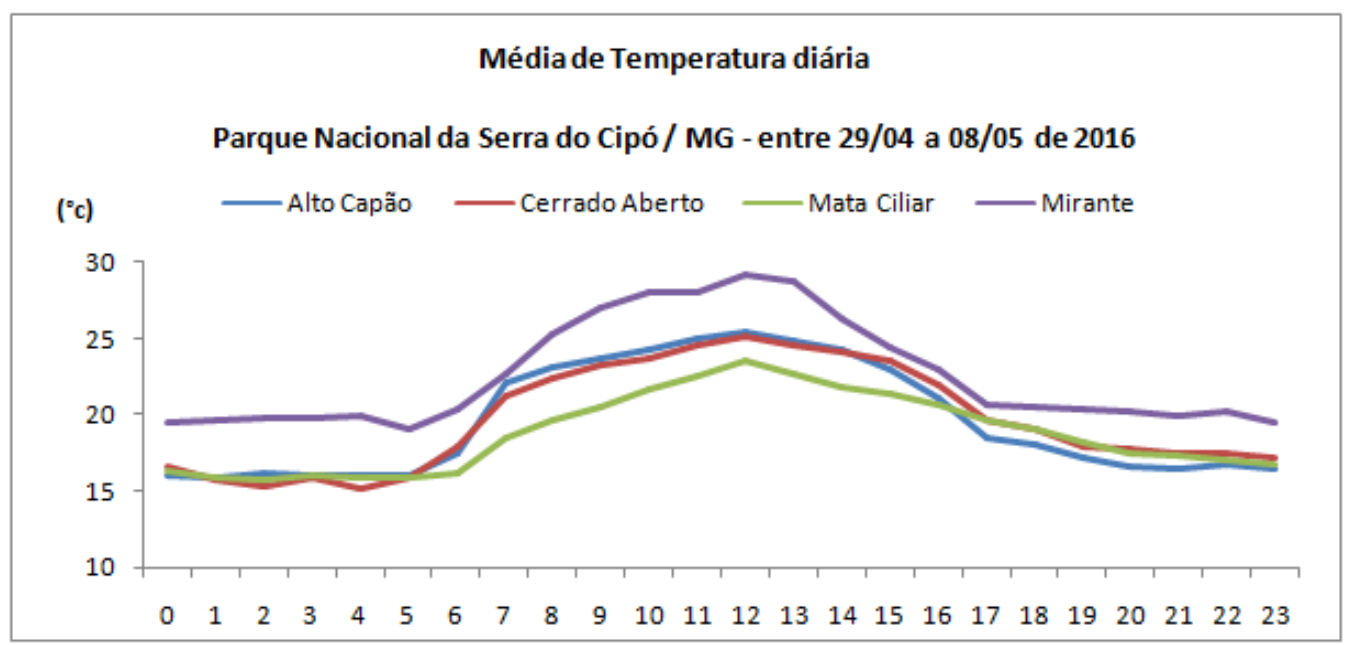

Figura 3. Gráfico de Médias de Temperatura diária obtidas nos abrigos meteorológicos - PNSC/MG

Nos abrigos meteorológicos instalados em área com cobertura vegetal em regeneração denominados Cerrado Aberto e Alto Capão não houve oscilações expressivas. Já no abrigo instalado em Mata Ciliar houve oscilação inferior de $4^{\circ} \mathrm{C}$ em comparação aos primeiros no período de incidência da radiação solar. O que já era esperado em função da cobertura vegetal arbórea densa que interceptará grande parte da radiação solar, juntamente com a presença de curso d'água nas proximidades, regulando as variações de temperatura e umidade relativa do ar. Assim a evaporação da água e evapotranspiração das plantas consomem parte do calor sensível e o transforma em calor latente (que não participa das variações de 
temperatura); outra parte é consumida pelo metabolismo das plantas e armazenada na forma de biomassa.

Portanto, comparado aos demais postos, o saldo de energia é baixo, o que explica os baixos valores de temperatura neste ponto de medição. Na mensuração realizada às 12 horas é possível perceber o contraste (FIG. 3).

Sobre a Umidade Relativa do Ar, as médias diárias para este parâmetro (FIG. 4) indicam um comportamento padrão para os dados registrados nos quatro abrigos.

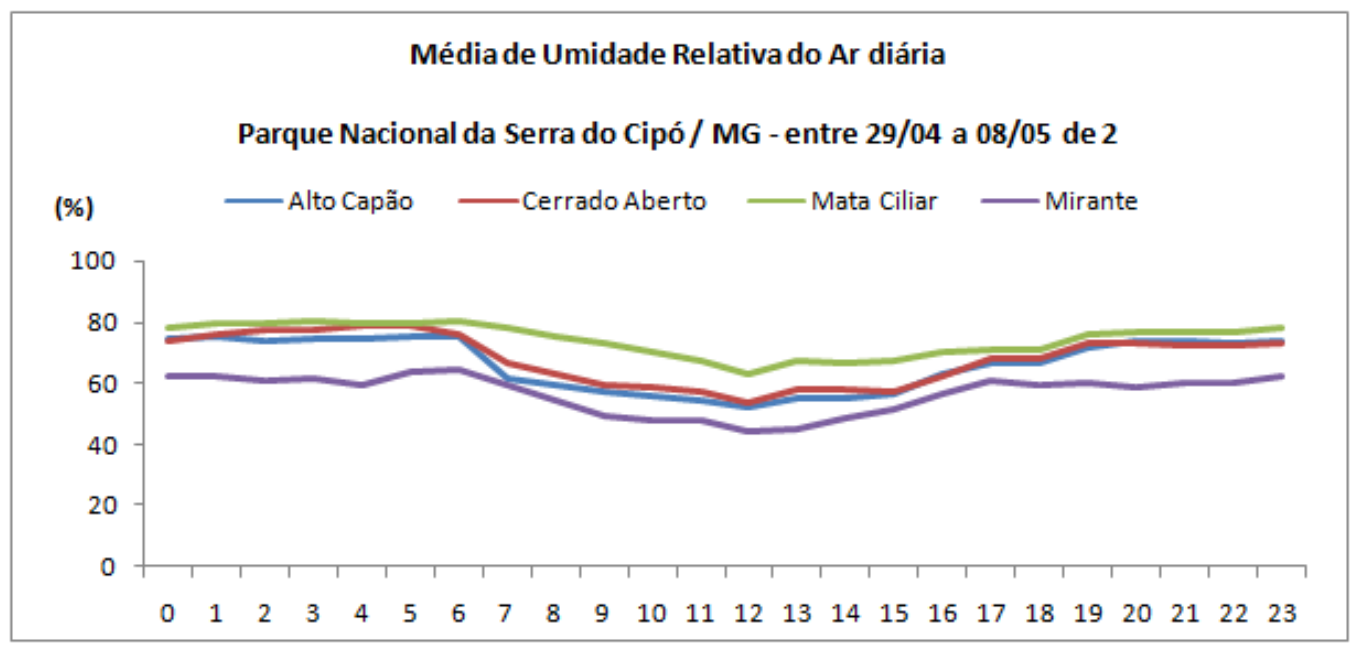

Figura 4. Gráfico de Médias de Umidade Relativa do Ar diária obtidas nos abrigos meteorológicos - PNSC/ MG

No período noturno, a elevada umidade relativa do ar (por volta de 80\%), remete a ocorrência de orvalho. E, ao amanhecer, as primeiras horas de radiação solar elevam a temperatura e dissipam o excesso de água no solo, reduzindo a umidade, contudo ainda se preservando elevada, por volta de $50 \%$, registrado nas horas de maior radiação (12 as 15 horas). Tais valores reafirmam a importância da cobertura vegetal para retenção de umidade próxima ao solo, mesmo no período de seca (outono). Já no abrigo Mirante a umidade relativa ficou próxima de 44\%, explicada pela combinação entre altitude elevada (900m), localização em meia vertente; cobertura vegetal de pequeno porte, típica de Campo Rupestre, com solo raso e rochas aflorantes, e ainda pela atuação dos ventos locais, que é mais intensa nessa altitude. No abrigo Mata Ciliar, por sua vez, a umidade relativa do ar apresentou comportamento esperado com pouca oscilação e maiores valores (até $23 \%$ de umidade a mais do que a leitura no ponto de Mirante as 9 horas), em função da proximidade com o rio e pela existência da cobertura vegetal arbórea, como atenuadora térmica. 


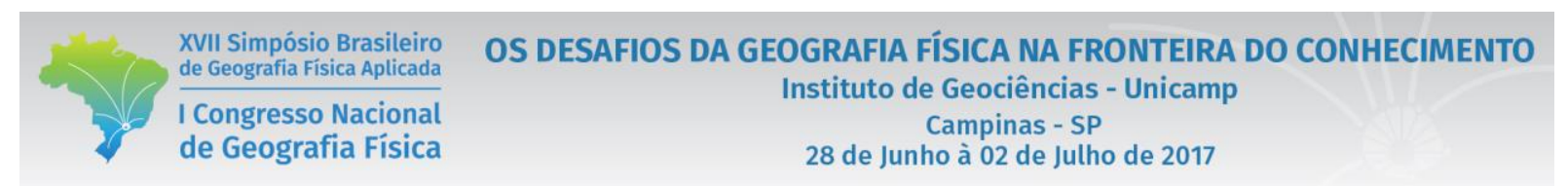

Por fim, na figura 5, nota-se que os valores de ponto de orvalho para os quatro abrigos apresentam comportamento análogo, em especial o abrigo do Mirante. Neste, o ponto de orvalho é atingido mais facilmente, pois os menores valores de temperatura favorece a saturação e a formação de condensação do ar. Nota-se ainda que os valores obtidos coincidem com os máximos de Umidade Relativa do Ar e Mínimas de Temperaturas, no intervalo entre as $22 \mathrm{~h}$ e $5 \mathrm{~h} 30 \mathrm{~m}$, também associados à maior ocorrência da saturação do ar, favorecida pela atuação dos ventos catabáticos durante a madrugada e pela forte dissipação de calor para a baixa troposfera em função da reduzida nebulosidade verificada para o período.

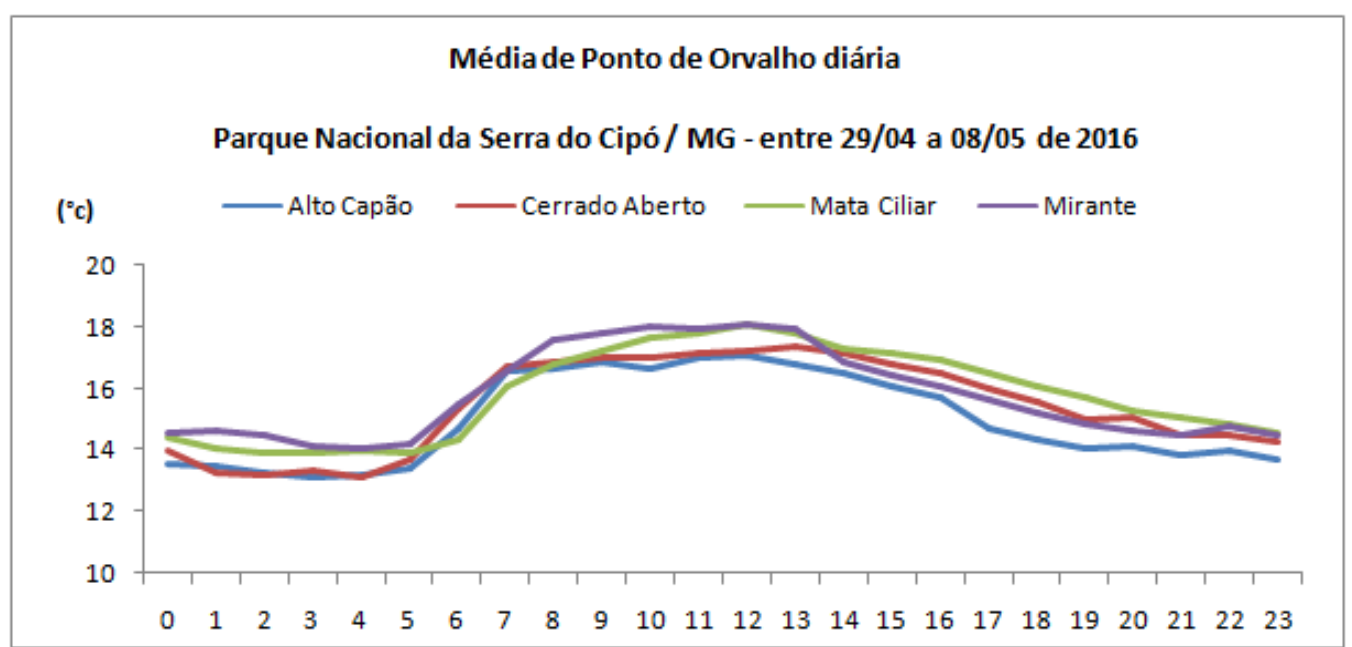

Figura 5. Gráfico de Médias de Pontos de Orvalho diária obtidas nos abrigos meteorológicos - PNSC/MG

A associação entre os diversos fatores e elementos climáticos para os quatro pontos observados ratificam o comportamento climático esperado para a região em estudo, que se configuram a partir da combinação de variáveis geográficas múltiplas, que se definem, em especial, sobre a relação entre os fatores da mesoescala, tais como as variações de altitude da área, determinadas de modo predominante pela formação do orógeno do Espinhaço e do afloramento rochoso. Portanto, a configuração de climas regionais dialoga com as ideias apresentadas por Sorre (2006) e Jesus (2008), na medida em que as variáveis climáticas da Serra do Cipó são definidas de modo predominante pela influência de fatores geográficos controladores do clima, entre outros fatores estáticos.

\section{Considerações Finais}


$\mathrm{Na}$ análise dos dados climáticos pesquisados e coletados em campo foi possível constatar a importância e a atuação de alguns elementos e fatores reguladores e controladores das condições climáticas que afetam o clima local, todavia sofrem influência do clima regional, mostrando a integração entre o sistema superfície-atmosfera, típicos da mesoescala. A presença do orógeno do Espinhaço na área de estudo influencia e determina, de modo incisivo, as condições climáticas da região, refletidas na configuração da vegetação, compartimentada pela altitude, profundidade e tipo de solo, bem como pela atuação antrópica sobre esta. Com destaque para a atuação de desmatamentos e queimadas no entorno do Parque Nacional da Serra do Cipó e que podem ocasionar em uma alteração do microclima com diminuição da umidade relativa do ar por valores extremos de temperatura. Por isso a atuação de órgãos fiscalizadores e de conservação e proteção ambiental sobre a área se tornam essenciais para a manutenção deste "patrimônio ambiental" do estado de Minas Gerais, bem como, para garantir que as espécies da fauna e da flora, vale ressaltar, região com expressivo endemismo, não sejam extintas. Assim como, cabe reafirmar que o turismo realizado sobre os atrativos do Parque, em especial sobre as cachoeiras, deve ser feito a partir de princípios de sustentabilidade e responsabilidade ambiental.

Conclui-se que, apesar das condições climáticas serem configuradas por elementos e fatores diversos, a ação humana depredatória - ao menos em escala local - é capaz de modificar a configuração da paisagem e comprometer a sobrevivência tanto de espécies da biota regional quanto o meio de subsistência de comunidades tradicionais e moradores locais, que baseiam sua atividade econômica sobre o extrativismo de espécies do Cerrado e do Campo Rupestre para a confecção de artigos de artesanato ou para atividades agropastoris. Desta forma, preservar a biodiversidade é essencial em áreas como esta, caracterizada por Gontijo (2008) como um "mosaico de biomas". Portanto, se as condições climáticas, nesta escala, são reflexos da combinação destes fatores, caso sejam alterados pela ação humana, pressupõe-se que a natureza se encarregará de adaptá-las às novas condições morfo-bio-climáticas, seguindo a lógica de equilíbrio e de organização dos sistemas climáticos.

\section{Bibliografia}

BRASIL. Decreto Federal $n^{\circ}$ 90.223, de 25 de setembro de 1984. Cria, no Estado de Minas Gerais, o Parque Nacional da Serra do Cipó e dá outras providências. Diário Oficial da União - Seção 1, 26 set. 1984.

CPTEC. Disponível em: 〈http://satelite.cptec.inpe.br/acervo/goes.formulario.logic〉. Acesso em: 30 maio 2016.

GONTIJO, B. M. Uma geografia para a Cadeia do Espinhaço. Belo Horizonte: Megadiversidade, v. 4, n. 1-2, p.715, dez. 2008.

INSTITUTO BRASILEIRO DE GEOGRAFIA E ESTATÍSTICA - IBGE. Carta topográfica: Baldim. Rio de Janeiro: IBGE, 1975. Não paginado. Escala 1: 100.000. Folha: SE.23-Z-C-III. 
INSTITUTO NACIONAL DE METEOROLOGIA - INMET. Normais Climatológicas do Brasil 1961-1990 / RAMOS, A. M.; SANTOS, L. A. R.; FORTES, L. T. G (Org.). Brasília: INMET, 2009. 465p.

JESUS, E. F. R. Algumas reflexões teórico-conceituais na climatologia geográfica em mesoescala: uma proposta de investigação. Salvador: UFBA - GeoTextos, v.4, n.1 e 2, p.65-187, 2008.

MARINHA DO BRASIL. Disponível em: <https://www.mar.mil.br/dhn/chm/meteo/prev/cartas/cartas.htm>. Acesso em: 30 maio 2016.

MONTEIRO, C. A. F. Análise rítmica em Climatologia. Problemas da atualidade climática em São Paulo e achegas para um programa de trabalho. São Paulo: Climatologia, n. 1, 1971. p.1-21.

SORRE, M. Objeto e Método da Climatologia. Revista do Departamento de Geografia. São Paulo: FFLCH/USP, v.18, p.89-94. 2006. Tradução de José Bueno Conti. 